Valdilene Josefa de Santana ${ }^{1}$ José Ronaldo Vasconcelos Nunes ${ }^{1}$

\title{
COMPREENSÃO DOS MEMBROS DO MINISTÉRIO PÚBLICO DO INTERIOR DE PERNAMBUCO SOBRE AS POLÍTICAS PÚBLICAS DE SAÚDE
}

How public prosecutors of the countryside of Pernambuco State in Brazil understands public health polices

${ }^{1}$ Núcleo de Saúde Coletiva. Centro Acadêmico de Vitória. Universidade Federal de Pernambuco. Recife/PE, Brasil.

Correspondência: José Ronaldo Vasconcelos Nunes. E-mail: ronatriunfo@yahoo.com.br

Recebido: 15/03/2018. Revisão: 27/05/2018. Nova revisão: 08/08/2018. Aprovado: 09/08/2018. 


\section{RESUMO}

A oferta do direito à saúde no Brasil, constitucionalmente prevista de forma universal e integral, possibilitou avanços no desenvolvimento das políticas públicas do setor. A atribuição delegada ao Ministério Público de fiscalizar e garantir a efetivação das referidas políticas vem exigindo, recentemente, uma atuação mais efetiva dessa instituição. O mesmo observa-se no cotidiano de trabalho do sistema judiciário. Este artigo objetiva descrever a compreensão dos membros do Ministério Público sobre as políticas públicas de saúde, utilizando-se de estudo qualitativo, realizado por meio de entrevistas com promotores de justiça de comarcas localizadas no interior do Estado de Pernambuco. Os dados coletados foram analisados pelas técnicas de análise de conteúdo e de análise temática. Encontraram-se na fala dos entrevistados três categorizações para interpretação. Na primeira, o Estado, incumbido de garantir a efetivação do direito subjetivo à saúde, vem apresentando fragilidade na concretização de seu papel de devedor, frente à condição de credor do cidadão. Essa vulnerabilidade reflete-se na segunda categoria: o aumento da judicialização da saúde, apontada como uma realidade crescente e complexa no trabalho cotidiano dos promotores. Identificou-se, como terceira categoria, que a formação acadêmica do bacharel em direito apresenta lacunas relacionadas ao estudo das políticas públicas sociais, dentre elas as relacionadas ao Sistema Único de Saúde. Existe uma fragilidade na compreensão dos membros do Ministério Público sobre as políticas públicas de saúde, tornando necessário o aprofundamento científico por meio de estudos que explorem a relação entre o Ministério Público e a saúde coletiva.

\section{Palavras-Chave}

Direito à Saúde; Ministério Público; Políticas Públicas.

\section{ABSTRACT}

The right to health in Brazil, which is constitutionally guaranteed as universal and integral, has led to significant advances in the development of public health policies. The task of supervising and ensuring the correct implementation of these public policies has been delegated to the Public Prosecutor's Office, from which a more effective intervention has been recently required. The same activity can be observed from the judiciary system. This article aims at describing the understanding of the Public Prosecutor's Office on public health policies. This was done using the qualitative study method, by interviewing public prosecutors of regions of the countryside of Pernambuco state. The data was examined through thematic analysis and content analysis. The speeches of the interviewed showed three interpretation categories. In the first category, the State, which is responsible for the accomplishment of the subjective right to health, has been presenting fragilities in fulfilling its role. This vulnerability reflects in a higher judicialization of healthcare, which is the second category and it is indicated as an increasing and complex reality in the day-to-day work of prosecutors. The third category identified is a lack of adequate at the level of Bachelor in Law Degrees in Brazil about public and social policies, especially in the area of the Brazilian National System. There is a limited comprehension among Prosecutors of the public health policies which makes necessary more scientific studies to explore the relationship between Public Prosecutor's Office and the area of public health.

\section{Keywords}

Right to Health; Public Prosecutor's Office; Public Policies. 


\section{Introdução}

A conjuntura no Brasil pós-Segunda Guerra Mundial apresentou grandes restrições na oferta de direitos fundamentais à vida da população, evidenciadas no longo período de ausência de democracia plena a partir do regime militar, vigente entre 1964 e 1985. Isso fez do dia 5 de outubro de 1988 um marco importantíssimo para a reversão desse cenário: naquele dia, a promulgação da Constituição da República Federativa do Brasil $(\mathrm{CF} / 88)^{1}$ assegurou à sociedade direitos até então inexistentes.

Na Carta Magna de 1988, conhecida como "Constituição Cidadâ", um conjunto de direitos foi legalmente estabelecido, trazendo importantes avanços para a sociedade, com destaque para o trecho compreendido entre os artigos $196 \mathrm{e}$ 200, que diz respeito ao reconhecimento da saúde como direito de cidadania. Essa conquista foi fruto de reivindicações da sociedade civil organizada, mobilizada em torno do movimento da Reforma Sanitária brasileira² ${ }^{2}$. A legislação estabeleceu que o Estado tem o dever de garantir o acesso às políticas que visam à garantia da saúde da população e aos bens e serviços de saúde que se façam necessários a todos os brasileiros. A saúde foi estabelecida como direito fundamental, assegurando assim assistência em saúde de forma integral e universal, independentemente de classe social, etnia, religião, raça ou região geográfica.

A proposta de sistema de saúde assumiu, então, o conceito ampliado de saúde como um paradigma importante, percebendo o indivíduo de forma integral e considerando a multicausalidade do processo saúde-doença. Como forma de colocar em prática essa nova concepção de saúde pública, foi instituído o Sistema Único de Saúde (SUS), regulamentado pela Lei n. 8.080/1990³ - que dispõe sobre as condições para a promoção, proteção e recuperação da saúde, a organização e o funcionamento dos serviços correspondentes - e pela Lei n. 8.142/19904 - que dispõe sobre a participação da comunidade na gestão do SUS e sobre as transferências intergovernamentais de recursos financeiros na área da saúde. Esse arcabouço legal ficou conhecido como as leis orgânicas da saúde.

Diante do compromisso social assegurado na carta constitucional em relação à área da saúde, que exigiu avanços e modificações na assistência à saúde

\footnotetext{
${ }^{1}$ BRASIL. Constituição da República Federativa do Brasil de 1988. Disponível em: http://www.planalto.gov. br/ccivil_03/constituicao/constituicaocompilado.htm. Acesso em: 10 set. 2019.

${ }^{2}$ AGUIAR, Zenaide Neto SUS: Sistema Único de Saúde: antecedentes, percurso, perspectivas e desafios. 2. ed. São Paulo: Martinari, 2015.

${ }^{3}$ BRASIL. Lei n. 8.080, de 19 de setembro de 1990. Dispõe sobre as condições para a promoção, proteção e recuperação da saúde, a organização e o funcionamento dos serviços correspondentes e dá outras providências. Disponível em: http://www.planalto.gov.br/ccivil_03/leis/l8080.htm>. Acesso em: 10 set. 2019. ${ }^{4}$ BRASIL. Lei n. 8.142, de 28 de dezembro de 1990. Dispõe sobre a participação da comunidade na gestão do Sistema Único de Saúde (SUS) e sobre as transferências intergovernamentais de recursos financeiros na área da saúde e dá outras providências. Disponível em: http://www.planalto.gov.br/ccivil_03/leis/L8142. htm. Acesso em: 10 set. 2019.
} 
da população, houve uma reorganização das políticas públicas no setor com o objetivo de implementar propostas governamentais a partir das diretrizes estabelecidas visando à melhoria da situação de saúde da população, na tentativa de garantir uma assistência de forma integral, universal e equânime aos cidadãos.

A missão de fiscalizar o efetivo cumprimento desses direitos foi atribuída ao Ministério Público (MP). Dispõe a CF/88, em seu artigo 127, que o MP tem a obrigatoriedade de defender a ordem jurídica, o regime democrático e os interesses sociais e individuais indisponíveis. A relevante atuação desse órgão independente tornou-se pauta na defesa da consolidação plena da saúde pública no Brasil.

Vários momentos institucionais do controle social da saúde reafirmam, em seus documentos oficiais, a importância do MP para a consolidação efetiva da prestação dos serviços de saúde. Podem ser destacados como marcos documentais o relatório final da $10^{\mathrm{a}}$ Conferência Nacional de Saúde, que faz menção ao dever do MP de assegurar o cumprimento da lei maior em prol da garantia do direito à saúde ${ }^{5}$. A Carta de Palmas em Defesa da Saúde (1998) também destaca o papel fiscalizador que o órgão desempenha para a garantia da assistência universal, igualitária e integral $^{6}$. A Carta de Salvador em Defesa da Saúde (2004), cujo principal elemento é a defesa da saúde ${ }^{7}$, e o Plano Nacional de Atuação do Ministério Público em Saúde $(2006)^{8}$ são documentos que explicitam os estímulos formais para a atuação do MP no setor da saúde.

Ao verificar a trajetória do MP no Brasil, identifica-se que sua criação teve o intuído de estabelecer um órgão que defendesse os interesses do Estado. A CF/88 dispôs a atuação de um novo MP: a instituição deixou de ser um órgão vinculado ao Poder Executivo e passou a ser autônomo ${ }^{9}$. Com essa nova conjuntura estabelecida, observa-se que as mudanças em suas atribuições buscam maior intervenção do órgão para atender aos direitos e interesses de ordem social.

\footnotetext{
${ }^{5}$ RELATÓRIO Final da $10^{\text {a }}$ Conferência Nacional de Saúde. "SUS - construindo um modelo de atenção à saúde para a qualidade de vida". Brasília, 2-6 set. 1996. Coordenador da Comissão Organizadora Nelson Rodrigues dos Santos. Disponível em: bvsms.saude.gov.br/bvs/publicacoes/10conferencia.pdf. Acesso em: 28 set. 2016.

${ }^{6}$ CONSELHO NACIONAL DE SECRETARIAS MUNICIPAIS DE SAÚDE - CONASEMS. Carta de Palmas. In: CONGRESSO NORTE E NORDESTE DE SECRETÁRIOS MUNICIPAIS DE SAÚDE, 4., Palmas, 18-20 abr. 2016. Disponivel em: http://www.conasems.org.br/wp-content/uploads/2016/05/images_CARTA_DE_PALMAS. pdf. Acesso em: 02 out. 2016.

${ }^{7}$ MINISTÉRIO PÚBLICO DO CEARÁ - MPCE. Carta de Salvador em Defesa da Saúde. Salvador-BA, 27 ago. 2004. Disponivel em: http://www.mp.ce.gov.br/orgaos/PROSAUDE/cartas_declaracoes_salvador.html. Acesso em: 02 out. 2016.

${ }^{8}$ MINISTÉRIO PÚBLICO DO ESTADO DO ESPíRITO SANTO. Plano Nacional de Atuação Ministerial em Saúde Pública. 2006. Disponível em: https://www.mpes.mp.br/Arquivos/Anexos/72bd6d29-2df4-433b-a821c2cb7f15ce42.pdf. Acesso em: 19 out. 2019.

${ }^{9}$ CARVALHO, Ernani, LEITAO, Natália. O novo desenho institucional do Ministério Público e o processo de judicialização da política. Rev. direito GV, São Paulo, v. 6, n. 2, p. 399-422, dez. 2010. http://dx.doi. org/10.1590/S1808-24322010000200003. Disponível em: http://www.scielo.br/scielo.php?script=sci_ arttext\&pid=S1808-24322010000200003\&lng=en\&nrm=iso. Acesso em: 15 nov. 2017.
} 
O MP pode ser compreendido como uma instituição indispensável para que o Poder Judiciário funcione. Ele tem uma função essencial na justiça, pois permite que seja suplantada a atuação juridicamente estática do referido Poder. $\mathrm{O}$ fato de o MP não precisar ser provocado pelo interessado se faz extremamente condizente com as necessidades da saúde se efetivar como direito fundamental de cidadania, necessidades estas garantidas por políticas estatais não apenas por meio do direito objetivo, mas também de um vasto e complexo conteúdo normativo infralegal que, inclusive, dialoga com as instituições sociais, pois o interesse do objeto saúde não diz respeito a pessoas determinadas, mas a toda a coletividade. Essa situação está relacionada com a garantia processual e material do MP, que possui independência funcional para interferir de acordo com o interesse público sobre problemas associados à promoção e assistência à saúde ${ }^{10}$.

É dever do Ministério Público fiscalizar e assegurar o cumprimento dos direitos garantidos nas leis orgânicas da saúde ${ }^{11}$. Fica sob responsabilidade do MP, mas não apenas dele, a efetivação das normas constitucionais, atuando a fim de fornecer a fiscalização do cumprimento das políticas públicas. Estas "políticas públicas podem ser definidas como o conjunto de disposições, medidas e procedimentos que traduzem a orientação política do Estado e regulam as atividades governamentais relacionadas às tarefas de interesse público" ${ }^{12}$. A relevância do MP foi destaque no relatório da $10^{\text {a }}$ Conferência Nacional de Saúde, em 1996, em que foi sugerido que "os gestores do SUS e os Conselhos de Saúde devem exigir do MP a defesa do SUS e das demais políticas que atuam na ampliação e manutenção da qualidade de vida da população"13.

As possíveis deficiências na oferta do direito à saúde exigem do MP um conhecimento amplo na área e uma atuação precisa; até porque, hoje, observa-se um aumento da cobrança do cumprimento e da efetivação de direitos sociais via sistema judicial. A conjuntura atual evidencia uma relação mais efetiva entre o MP e o setor saúde devido à expansão da judicialização das questões relacionadas à saúde. São inúmeras as cobranças por via judicial de consultas, exames, medicamentos, internações em leitos de Unidade de Tratamento Intensivo (UTI), entre outras, e isso exige uma compreensão mais aguçada do que realmente é essencial

${ }^{10}$ ASENSI, Felipe Dutra. Judicialização ou juridicização? As instituições jurídicas e suas estratégias na saúde. Physis, Rio de Janeiro, v. 20, n. 1, p. 33-55, 2010. http://dx.doi.org/10.1590/S0103-73312010000100004. Disponível em: http://www.scielo.br/pdf/physis/v20n1/a04v20n1.pdf.

${ }^{11}$ CONSELHO NACIONAL DE SECRETÁRIOS DE SAÚDE - CONASS. Legislação do SUS. 20. ed. Brasília-DF: CONASS, 2003. p. 22-38. Disponível em: http://bvsms.saude.gov.br/bvs/publicacoes/progestores/leg sus.pdf. Acesso em: 10 set. 2019.

${ }^{12}$ LUCCHESE, Patricia T. R (Coord.). Políticas públicas em saúde pública. São Paulo: BIREME/OPAS/OMS, 2004. Disponível em: http://files.bvs.br/upload/M/2004/Lucchese_Politicas_publicas.pdf. Acesso em: 20 set. 2017.

${ }^{13}$ RELATÓRIO Final da $10^{\text {a }}$ Conferência Nacional de Saúde. "SUS - construindo um modelo de atenção à saúde para a qualidade de vida", cit. 
para a manutenção da vida, do impacto que uma demanda individual pode causar à coletividade e da valoração da relação entre direito individual e direito coletivo.

Devido à importância da relação entre o MP e a garantia das políticas públicas de saúde, e diante da preocupação constante e atual sobre as crescentes demandas que a judicialização da saúde levanta, torna-se importante a ampliação dos estudos sobre as práticas de todos os atores envolvidos nesse processo. Sendo assim, o presente estudo tem como objetivo descrever a compreensão dos membros do MP do interior de Pernambuco sobre as políticas públicas de saúde.

\section{Método}

O trabalho trata-se de um estudo de abordagem qualitativa, de caráter descritivo. A fim de obter a interpretação dos fenômenos, a pesquisa foi realizada no cenário habitual do objeto estudado (as unidades do Ministério Público de Pernambuco MPPE), buscando o posicionamento fidedigno dos detentores das informações (os promotores de Justiça). O caráter metodológico descritivo oportuniza a descrição criteriosa dos fatos e fenômenos da realidade em pauta, podendo também designar compreensões diferentes das existentes ${ }^{14}$. A abordagem utilizada, embora possa ser compreendida como original diante do público investigado e tenha se mostrado de difícil realização, permitiu a ampliação do conhecimento sobre o contexto jurídico que envolve a garantia do direito à saúde em Pernambuco.

O sistema judiciário de Pernambuco possui 150 comarcas, das quais 34 têm mais de uma cidade sobre sua responsabilidade - como é o caso de duas das quatro cidades da abrangência do estudo, todas localizadas na Zona da Mata do estado. $\mathrm{O}$ território pernambucano está subdividido em 14 circunscrições do MPPE; como a capital do estado não se enquadra nessa divisão por circunscrições, centraliza as demandas administrativas oriundas dos municípios pertencentes à determinada área geográfica. Dos quatro municípios estudados, dois pertencem à $11^{\text {a }}$ circunscrição e dois, à $12^{\mathrm{a} 15}$.

No aspecto da estrutura da saúde pública, visando a ofertar condições para a efetivação dos princípios e diretrizes do SUS, o processo de descentralização e regionalização da saúde se deu em Pernambuco pela implantação de 12 Gerências Regionais de Saúde (Geres) e de 11 Microrregiões de Saúde. Cada Geres é responsável

\footnotetext{
${ }^{14}$ AUGUSTO, Cleiciele Albuquerque et al. Pesquisa qualitativa: rigor metodológico no tratamento da teoria dos custos de transação em artigos apresentados nos congressos da Sober (2007-2011). Rev. Econ. Sociol. Rural, Brasília-DF, v. 51, n. 4, p. 745-764, dez. 2013. http://dx.doi.org/10.1590/S010320032013000400007. Disponível em: http://www.scielo.br/scielo.php?script=sci_arttext\&pid=S0103$20032013000400007 \& \operatorname{lng}=e n \& n r m=i s o$. Acesso em: 01 nov. 2017.

${ }^{15}$ MINISTÉRIO PÚBLICO DE PERNAMBUCO - MP/PE. Guia do Ministério Público de Pernambuco - Informações para a sociedade e a imprensa. Recife: Procuradoria Geral da Justiça, 2015. Disponível em: www.mppe. mp.br/mppe/attachments/article/5350/Manual\%20MPPE\%20final\%20correto\%20site.pdf. Acesso em: 11 maio 2016.
} 
pela coordenação e articulação dos serviços de suas Microrregiões ${ }^{16}$. Essas subdivisões das Regiões de Saúde foram criadas para promover maior acesso aos usuários, servindo de base para o planejamento e a articulação das ações da gestão. As unidades do MPPE escolhidas para o estudo ficam localizadas em cidades que compõem a I e a II Geres, e que fazem parte da II, da IV e da V Microrregiões de Saúde do estado. Optou-se aqui por não divulgar os nomes dos municípios, a fim de manter a identidade dos entrevistados em sigilo.

A possibilidade de obter a compreensão dos membros do MPPE que atuam em cidades de menor porte sobre as políticas públicas de saúde foi um dos critérios para a definição desses municípios interioranos. Como se propõe a análise de uma categoria subjetiva - a compreensão -, o presente estudo considera que o termo referido está diretamente relacionado ao ato de entender, dispor de um olhar analítico sobre os acontecimentos. "A compreensão não é um simples ato de identificação de informações, mas uma construção de sentidos com base em atividades inferenciais" ${ }^{17}$.

O estudo teve como população-alvo os promotores de Justiça, cuja importante função desenvolvida junto à sociedade é a defesa dos direitos sociais indisponíveis. São esses membros do poder público, juntamente com a instituição MPPE, que atuam em defesa das demandas da sociedade pernambucana, "intervindo nos espaços de negociação política como órgão mediador, regulador e corretor das desigualdades sociais"18. Participaram da pesquisa quatro promotores, atuantes em municípios pertencentes a $11^{\mathrm{a}}$ e $12^{\mathrm{a}}$ circunscrições do MP do Estado de Pernambuco, independentemente do tempo de serviço, que tinham disponibilidade para contribuir com o estudo.

No primeiro momento, houve o contato telefônico com as secretarias dos órgãos do MPPE, em busca de informações sobre os requisitos impostos pelos membros para a concessão da entrevista. No segundo momento, foram feitas visitas às sedes do MPPE dos referidos municípios, com o objetivo de expor a relevância do estudo para os campos específicos do direito e da saúde coletiva, bem como para a sociedade em geral. Posteriormente, houve a realização das entrevistas gravadas com os membros do MPPE, seguidas de transcrição e análise do conteúdo.

\footnotetext{
${ }^{16}$ BRASIL. Decreto n. 7.508, de 28 de junho de 2011. Regulamenta a Lei no 8.080, de 19 de setembro de 1990, para dispor sobre a organização do Sistema Único de Saúde - SUS, o planejamento da saúde, a assistência à saúde e a articulação interfederativa, e dá outras providências. Brasília, 28 de junho de 2011. Disponível em: http://www.planalto.gov.br/ccivil_03/_ato2011-2014/2011/decreto/D7508.htm. Acesso em: 20 set. 2016.

${ }^{17}$ MARCUSCHI, Luiz Antônio. Compreensão textual como trabalho criativo. In: UNIVERSIDADE ESTADUAL PAULISTA. Prograd. Caderno de formação: formação de professores didática geral. São Paulo: Cultura Acadêmica, 2011. p. 89-103, v. 11. Disponível em: https://acervodigital.unesp.br/ handle/123456789/40358. Acesso em: 10 out. 2017.

${ }^{18}$ GOULART, Marcelo Pedroso. Ministério Público: estratégia, princípios institucionais e novas formas de organização. In: LIVIANU, R. (Coord.). Justiça, cidadania e democracia [online]. Rio de Janeiro: Centro Edelstein de Pesquisa Social, 2009. p. 158-169. Disponível em: books.scielo.org/id/ff2x7/pdf/ livianu-9788579820137-14.pdf. Acesso em: 10 out. 2017.
} 
O material devidamente transcrito foi analisado a partir do método de análise de conteúdo, na modalidade de análise temática, para a organização dos dados da pesquisa, "buscando descobrir os núcleos que compõem a comunicação, cuja presença ou frequência signifiquem algo para o objeto analítico visado"19. A análise foi composta por três etapas: (i) pré-análise; (ii) exploração do material e tratamento dos resultados obtidos; e (iii) interpretação, processada a partir de um conjunto de técnicas de análise das comunicações, que incluíram procedimentos sistemáticos e objetivos de descrição do conteúdo das mensagens ${ }^{20}$.

Todos os entrevistados assinaram o termo de consentimento livre e esclarecido (TCLE). A pesquisa foi submetida ao Comitê de Ética em Pesquisa da Universidade Federal de Pernambuco (CEP-UFPE) sob a CAAE: 71475517.0.0000.5208.

\section{Análise e discussões}

O estudo descreveu a compreensão que os promotores de justiça membros do MPPE têm sobre políticas públicas de saúde, buscando identificar quais obstáculos impossibilitam a plena atuação para a concretização do direito à saúde junto à população da Zona da Mata de Pernambuco. O primeiro momento da análise das quatro entrevistas realizadas levou à identificação de três categorias temáticas, a saber: (i) a fragilidade do compromisso do Estado na efetivação do direito à saúde; (ii) o crescimento desordenado da judicialização da saúde; (iii) a deficiência no ensino do direito, especificamente dos conteúdos relacionados às políticas públicas, às políticas sociais e ao direito à saúde.

\section{Fragilidade do Estado na efetivação do direito à saúde}

O direito à saúde, garantido pela $\mathrm{CF} / 88$ e pela legislação ordinária, assegurou que todos, sem exceções, devem usufruir de uma assistência integral via serviços e ações de saúde. Para tanto, ficou sob a responsabilidade dos três entes federativos União, estados e municípios - a disponibilização da assistência à saúde de acordo com o grau de necessidade e a particularidade dos usuários, conforme artigo 23, II, da $\mathrm{CF} / 88$. Os achados na pesquisa indicam que, na prática que vivenciam, os membros do MPPE identificam que o Estado "é falho" no que diz respeito ao cumprimento efetivo de seu papel junto à sociedade.

Com todos os direitos que foram guardados à população na área de saúde em 1988, tanto em nível estadual quanto federal, não vem conseguindo cumprir de fato a efetivação desses direitos. (Entrevistado II; Zona da Mata de Pernambuco, $11^{\text {a }}$ circunscrição do MPPE, 26/09/2017.)

\footnotetext{
${ }^{19}$ MARCUSCHI, Luiz Antônio. op. cit.

${ }^{20}$ AUGUSTO, Cleiciele Albuquerque et al. p. 745-764.
} 
Os entrevistados entendem que existe um desajuste na atuação estatal ao ofertar saúde de forma integral conforme a necessidade do conjunto dos cidadãos. Sem um maior aprofundamento teórico e sem demonstração exata sobre a origem dos problemas, os promotores identificam que essa política pública, caracterizada pela não ação do Estado em suas práticas de saúde, acaba desenvolvendo impasses que ocasionam falhas na resolução das demandas e na oferta dos serviços e ações de saúde.

A dificuldade principal, sem sombra de dúvidas, é a falha do poder público [...] das próprias condições de funcionamento das próprias unidades de saúde, sejam municipais, sejam estaduais, sejam de baixa complexidade, [sejam] de 'grande' complexidade. Hoje em dia, nós nos debruçamos sobre um poder público [...] que deixa bastante a desejar na prestação desse serviço de saúde, e isso eu falo de todas as esferas [...] essa falha do Estado e essa sua incapacidade de responder à demanda da sociedade $[. .$.$] com$ certeza demonstra-se como a principal dificuldade que temos hoje, na atuação e garantia do direito indisponível à saúde." (Entrevistado III; Zona da Mata de Pernambuco, 11 a circunscrição do MPPE, 05/10/2017.)

Na compreensão dos promotores, o Estado é o principal responsável pelo descumprimento das leis constitucionais, que reflete diretamente no déficit da oferta de serviços e/ou assistência a uma parcela da população. Isso contradiz o que é preconizado no conjunto de leis e normatizações da saúde, evidenciando uma lacuna na estrutura brasileiro de Estado que vai contra os preceitos constitucionais e comprovando que "vivemos, ainda, um ambiente com déficit de efetividade de uma série de direitos, não sendo o direito fundamental à saúde uma exceção"21.

O mais difícil são as limitações que o Estado oferece em termos de vagas nos hospitais, medicação, principalmente com as medicações de média e maior complexidade. Essa é uma grande luta que se tem. (Entrevistado II).

No Brasil, fica sob responsabilidade do Estado a organização e a oferta dos deveres legais de proteção à saúde no âmbito individual e coletivo, bem como o fornecimento dos meios para a assistência a todos os cidadãos ${ }^{22}$. Por esse motivo, se o

\footnotetext{
${ }^{21}$ OLIVEIRA, Gustavo Justino de. Efetivação do direito à saúde: ampliação do debate e renovação da agenda. Revista de Direito Sanitário, São Paulo, v. 16, n. 1, p. 78-86, jul. 2015. http://dx.doi. org/10.11606/issn.2316-9044.v16i1p78-86. Disponível em: http://www.revistas.usp.br/rdisan/article/ view/100024/98613. Acesso em: 30 out. 2017.

${ }^{22}$ VENTURA, Miriam et al. Judicialização da saúde, acesso à justiça e a efetividade do direito à saúde. Physis, Rio de Janeiro, v.20, n. 1, p. 77-100, 2010. http://dx.doi.org/10.1590/S0103-73312010000100006. Disponivel em: http://www.scielo.br/scielo.php?script=sci_arttext\&pid=S0103-73312010000100006\&ln g=en\&nrm=iso. Acesso em: 30 out. 2017.
} 
Estado não desenvolver suas atribuições de forma organizada e correspondente às necessidades sociais, desencadeará um processo de escassez dos direitos e a procura por meios judiciais para sua efetivação, considerando a condição da saúde como direito subjetivo.

O direito à saúde é um direito subjetivo com dimensão social, assim, no momento em que se o evoca para denegá-lo ou reconhecê-lo, a decisão deve considerar, caso a caso, a dimensão da repercussão social da decisão individual proferida ${ }^{23}$.

\section{Judicialização como forma de garantia do direito: a atuação do MP}

$\mathrm{O}$ ato de judicializar diz respeito a questões relevantes do ponto de vista político, social ou moral que estão sendo decididas, em caráter final, pelo Poder Judiciário $^{24}$. A judicialização da saúde é a reivindicação por via judicial da concretização do direito à saúde, oriunda de demanda individual ou coletiva. No cenário democrático atual, a debilidade na plena efetivação da assistência à saúde vem ocasionando um crescimento significativo da judicialização - fenômeno que foi surgindo com o passar dos anos, oriundo de reivindicações pelo cumprimento dos direitos assegurados constitucionalmente.

A exigibilidade do direito coletivo e/ou individual de forma judicial tem se tornado uma prática rotineira na atuação do $\mathrm{MP}$, devido à prestação da assistência integral deficitária oriunda das três esferas de governo, ao parco financiamento e ao mau gerenciamento dos serviços públicos.

A judicialização da saúde é praticamente uma tônica do MP atual, e em face principalmente das falhas do poder público estatal. (Entrevistado III)

A judicialização da saúde [...], infelizmente, se faz necessária muitas vezes em virtude das demandas públicas. Diante da inércia do poder público em atender as demandas sociais, por isso que tem que se judicializar. Em função da inércia do poder público. (Entrevistado IV; Zona da Mata de Pernambuco, 12a circunscrição do MPPE, 24/10/2017.)

\footnotetext{
${ }^{23}$ WERNER, Patrícia Ulson Pizarro. O direito social e o direito público subjetivo à saúde: o desafio de compreender um direito com duas faces. Revista de Direito Sanitário, São Paulo, v. 9, n. 2, p. 92-131, jul 2008. Disponível em: http://www.periodicos.usp.br/rdisan/article/view/13119/14922. Acesso em: 06 nov. 2017.

${ }^{24}$ BARROSO, Luís Roberto. Constituição, democracia e supremacia judicial: direito e política no Brasil contemporâneo. Revista da Faculdade de Direito da UERJ, Rio de Janeiro, v. 2, n. 21, p. 1-50, jan./jun. 2012. https://doi.org/10.12957/rfd.2012.1794. Disponível em: http://www.e-publicacoes.uerj.br/index. php/rfduerj/article/view/1794. Acesso em: 06 nov. 2017.
} 
As ações judiciais vêm sendo pleiteadas com maior frequência em prol da obtenção de assistência à saúde; os procedimentos requeridos vão desde medicação oferecida na rede de atenção básica até procedimentos de alta complexidade, além de demandas que, muitas vezes, solicitam serviços e ações de saúde no âmbito nacional e internacional geralmente com altos custos financeiros. Diante do texto constitucional, que assegura o direito à saúde de forma integral, e sendo o MP o órgão responsável por garantir e defender os direitos dos cidadãos, é inevitável a reivindicação em algum momento desse direito via Judiciário ou MP. "Uma vez positivado constitucionalmente, o direito à saúde, estendido a todos, passou a ser reivindicado judicialmente como direito subjetivo público contra o Estado"25.

A judicialização tem aumentado bastante [...]; tanto o nível estadual quanto [o] federal não vêm conseguindo cumprir de fato a efetivação desses direitos de modo espontâneo, então a população, através do Ministério Público, através da Defensoria Pública, vem pleiteando esses direitos [...] através do Poder Judiciário, por conta justamente da omissão do Estado em efetivá-los. (Entrevistado II)

O povo procura muito o MP para a gente entrar com ações principalmente para obter remédios, fornecimento de remédios, e são remédios caríssimos. (Entrevistado I; Zona da Mata de Pernambuco, $12^{\mathrm{a}}$ circunscrição do MPPE, 11/09/2017.)

Os membros do MPPE relatam que recebem muitas demandas solicitando o cumprimento do direito à assistência à saúde, por diversas causas: omissão do Estado em disponibilizar serviços essenciais; condição rara de saúde; sistema desorganizado; bens e serviços (como exames e medicamentos) em muitos casos indispensáveis para a manutenção da vida; entre outros.

Está muito grande a judicialização mesmo porque o sistema [...] Sistema que não atua muito bem. (Entrevistado I)

A judicialização da saúde acaba sendo uma alternativa inevitável para a nossa atuação [...] e, quando for necessário, eu, pelo menos, continuarei fazendo. (Entrevistado III)

Dependendo do caso, o MP procura resolver consensualmente antes do procedimento de judicialização de fato; não se obtendo sucesso, aciona o sistema judiciário. Esse artifício para a garantia do direito à saúde apresenta uma complexidade considerável aos agentes envolvidos. A “judicialização da saúde”, fenômeno

${ }^{25}$ TORRONTEGUY, Marco Aurélio Antas. A saúde nas barras da Justiça: um estudo do posicionamento recente do Supremo Tribunal Federal. Revista de Direito Sanitário, São Paulo, v. 11, n. 2, p. 224-236, out. 2010. Disponível em: https://www.revistas.usp.br/rdisan/article/view/13215/15027. Acesso em: 31 out. 2017. 
multifacetado, expõe limites e possibilidades institucionais estatais e instiga a produção de respostas efetivas pelos agentes públicos do setor ${ }^{26}$.

Para além de fundamentar sua ação em teorias presentes no debate doutrinário e jurisprudencial - tais como as do "mínimo existencial", da "reserva do possível" e da "negação do retrocesso social", tão pertinentes nas decisões judiciais -, o MP promove o diálogo, uma estratégia privilegiada.

A atuação do MP na esfera extrajudicial conta com instrumentos que auxiliam a proteção da sociedade, como a audiência pública, a recomendação, a ação penal pública, o inquérito civil, a nota técnica, o termo de ajustamento de conduta e a ação civil pública. O termo de ajustamento de conduta (TAC) é um acordo que estabelece compromissos que devem ser cumpridos pela parte que cometeu alguma irregularidade ou dano; evita uma demanda judicial, tornando mais rápida a busca de soluções. Se não for cumprido, pode dar início a uma ação judicial de execução. O TAC precisa determinar o fim ou a alteração de uma situação irregular e, quando a situação gerou algum dano, precisa prever uma forma de o responsável repará-lo ou compensá-lo, sempre em benefício da sociedade, conforme parágrafo $6^{\circ}$, do artigo $5^{\circ}$, da Lei n. $7.347 / 1985^{27}$.

Desempenhando o protagonismo que lhe é peculiar no tocante à efetivação de direitos e à implementação de políticas públicas de saúde, do ponto de vista jurídico, o MP valoriza os processos de negociação, pactuação e concessão entre os diversos atores que precisam de um resultado construído consensualmente ${ }^{28}$.

\section{Deficiência na formação do MP sobre políticas públicas de saúde}

Além das dificuldades encontradas pelos promotores que atuam em regiões do interior de Pernambuco - como o acúmulo de funções, muitas vezes em mais de um município e com atribuições distintas (criminal, eleitoral, dentre outras) -, as limitações a sua atuação em questões relacionadas à saúde também podem ter origem na formação acadêmica em direito, graduação que é pré-requisito obrigatório para o exercício da função.

Os principais requisitos para o ingresso como agente do MP é ser bacharel em direito, devidamente habilitado pela Ordem dos Advogados do Brasil (OAB), e

\footnotetext{
${ }^{26}$ PEPE, Vera Lúcia Edais et al. A judicialização da saúde e os novos desafios da gestão da assistência farmacêutica. Ciênc. saúde coletiva, Rio de Janeiro, v. 15, n. 5, p. 2405-2414, ago. 2010. http://dx.doi. org/10.1590/S1413-81232010000500015. Disponível em: http://www.scielo.br/scielo.php?script=sci_ arttext\&pid=S1413-81232010000500015\&Ing=en\&nrm=iso. Acesso em: 31 out. 2017.

${ }^{27}$ BRASIL. Lei n. 7.347, de 24 de julho de 1985. Disciplina a ação civil pública de responsabilidade por danos causados ao meio-ambiente, ao consumidor, a bens e direitos de valor artístico, estético, histórico, turístico e paisagístico (VETADO) e dá outras providências. Disponível em: http://www.planalto.gov.br/ccivil_03/ leis/L7347orig.htm. Acesso em: 21 out. 2019..

${ }^{28}$ ASENSI, Felipe Dutra. op. cit.
} 
ter experiência prévia como advogado. Posteriormente à aprovação em concurso, segundo relatam os entrevistados, é realizado um curso preparatório sobre a prática diária do promotor; nesse curso, uma noção introdutória sobre saúde pública é passada de forma sucinta.

Existe o curso de integração. Quando tão logo sai a nomeação, nós passamos 30 dias ouvindo palestras e participando de alguns processos, o chamado curso de integração, para depois ir atuar nas comarcas. (Entrevistado IV)

[...] o curso de formação [...] durou pouco mais de um mês. A gente teve um curso com membros do MP mais experientes que nós, também eles nos passaram as suas experiências, o convívio prático. Tentaram aproximar a gente; fazer uma adaptação ao que nos esperava. (Entrevistado III)

Embora os membros do MP passem pela formação inicial sobre suas práticas e sobre o ambiente a que serão introduzidos a partir de sua contratação, fica claro na fala dos entrevistados que há uma limitação em sua formação no que diz respeito às políticas públicas de saúde.

Tivemos uma palestra com o pessoal do SUS, não estou lembrado o nome da pessoa porque faz muito tempo. [...] inclusive uma senhora, ela deu uma palestra para a gente sobre políticas públicas, o que a gente poderia fazer no interior com relação à saúde. (Entrevistado I)

O pouco contato do promotor com o campo da saúde pública apresenta-se frágil na própria fala dos promotores, que relatam limitações na abordagem do tema da saúde pública em sua formação acadêmica.

[...] para ser bem honesto, durante a faculdade, esse tema de judicialização, de controle, de apoio às políticas públicas [...] não foi tão difundido [...] minha experiência com políticas públicas originou-se eminentemente aqui, agora, dentro da minha atuação no MPPE. (Entrevistado IV)

Por depararem com demandas consideradas não habituais em sua atuação cotidiana, os promotores vivenciam dificuldades na interpretação do que vai além da estrutura legal no processo de respaldar o direito do cidadão. Os contratempos para pleitear esses direitos estão inseridos na complexidade que envolve a relação entre o Estado e o MP. O excesso de recursos utilizados pelo Estado, na tentativa de evitar as cobranças, é percebido como um obstáculo para a concretização do processo.

A principal dificuldade são os processos complexos [...] contra a Fazenda Pública. Então, a Fazenda Pública [...] tem um excesso 
de judicialização, [...] no sentido que ela recorre de tudo [...] $\mathrm{Na}$ verdade ela entra com agravo. Agravo é o seguinte: o juiz dá uma decisão preliminar, é chamado o Estado [...], vem uma procuradora. Qualquer que seja o valor, já entra com o agravo para o tribunal suspender, o tribunal quase sempre não tem dado ganho de causa ao Estado, e ele recorre, ou seja, é o excesso de recurso que o Estado tem. (Entrevistado I)

Segundo os membros do MPPE entrevistados, atuar em processos relacionados à saúde pública demanda tempo e exige conhecimentos específicos sobre o assunto - uma das dificuldades relatadas por eles diz respeito à complexidade desses processos. Com a intenção de suprir essa questão, os promotores públicos de Pernambuco podem contar com o Centro de Apoio Operacional das Promotorias (CAOP), responsável pelo suporte em áreas específicas, como é o da saúde, a fim de ajudar a tomada de decisões com subsídios para os desfechos das demandas.

A gente tem um CAOP, que é acionado quando a matéria exige um estudo maior, uma dedicação maior. A gente passa um e-mail para eles, um e-mail institucional, então eles mandam as peças, os modelos, as minutas das ações, eles mandam cartilhas, eles dão auxílio à gente para isso. (Entrevistado I)

O estudo das demandas relacionadas à saúde tem exigido dos promotores um olhar diferenciado, pois trata-se de um campo "novo" de atuação. O ensino do Direito no Brasil precisa adotar modelos curriculares que abordem pontos cruciais do cotidiano, presentes na sociedade brasileira, contribuindo efetivamente para o agir dos operadores do Direito e, assim, desarticulando o aumento de casos "simples" que se aglomeram no sistema de Justiça brasileiro e provocam arranjos na gestão pública muitas vezes conflitantes com as bases da organização do sistema de saúde.

A emergência dos chamados 'novos direitos', preocupados sobretudo com as relações interdisciplinares e com as dimensões sociais, políticas, econômicas e culturais da sociedade, faz-se necessária, destacando-se a ênfase na formação em conteúdos transdisciplinares daqueles que vão operar os sistemas de Justiça. Portanto, não se trata simplesmente de criar disciplinas ou produzir um currículo bem elaborado, o importante é que a interdisciplinaridade e a transversalidade se alimentem mutuamente, desembocando na transdisciplinaridade dos cursos de Direito brasileiros ${ }^{29}$.

\footnotetext{
${ }^{29}$ PAULA, Quenya Correa de; SANTOS, André Filipe Pereira Reid dos. Novos capitais em luta na magistratura Federal da $2^{\mathrm{a}}$ Região. Quaestio luris, Universidade do Estado do Rio de Janeiro, Rio de Janeiro, v. 10, n. 4, p. 2616-2636, out. 2017. http://dx.doi.org/10.12957/rqi.2017.28094. Disponível em: http://www.epublicacoes.uerj.br/index.php/quaestioiuris/article/view/28197/21901. Acesso em: 02 out. 2017.
} 
Estimular uma nova compreensão da realidade com a transdisciplinaridade na formação dos profissionais é essencial para o desenvolvimento de serviços/ações da Justiça voltados à garantia da integralidade social do cidadão.

\section{Considerações finais}

A presente pesquisa descreveu a compreensão dos membros do MPPE sobre políticas públicas de saúde. A implantação e o funcionamento do SUS visam à garantia do direito à saúde constitucionalmente assegurado e regulamentado, evidenciando que é dever dos entes federativos ofertar serviços de saúde em proporção suficiente para as demandas da população. O descumprimento desse dever ocasiona reivindicação judicial para sua efetivação.

A mesma Constituição que declara a saúde como direito também atribui ao MP, entre outras funções, a defesa dos interesses coletivos. Com direitos legalmente garantidos e uma instituição estabelecida para exigir a efetividade desses direitos, é de considerável importância que se explore cada vez mais, tanto no âmbito acadêmico quanto no das relações sociais e jurídicas, o universo que integra as ações do MP e da saúde, duas importantes instituições da estrutura de cidadania brasileira.

A realização desta pesquisa possibilitou ampliar o conhecimento sobre o campo que engloba saúde pública e MP a partir da visão dos próprios promotores. A fragilidade do Estado na efetivação do direito à saúde - uma das três categorias de conteúdo identificadas no estudo - é evidenciada nas falas dos entrevistados, que afirmam que o Estado não vem conseguindo cumprir plenamente suas responsabilidades relativas à assistência em saúde pública. Para eles, essa dificuldade do poder público em oferecer serviços de saúde conforme as demandas estabelecidas fragiliza o processo de assistência à população e aumenta o acionamento do MP e do Poder Judiciário na busca por serviços e ações de saúde, em demandas individuais ou coletivas. A consequente judicialização da saúde acaba por contrariar o que diz a CF/88 sobre a obrigatoriedade do Estado de organizar e oferecer os serviços de acordo com as particularidades de cada região, considerando a subjetividade dessa assistência.

Em outra categoria de análise encontrada, os promotores abordaram a judicialização da saúde como estratégia utilizada para garantir a efetividade da oferta de bens e serviços de saúde, lançando um olhar sobre a atuação do MPPE nessas situações. Os membros do MPPE identificam a judicialização como um "mal necessário" para a efetivação da assistência à saúde. A cobrança do direito à saúde por meio da Justiça é considerada pelos promotores como uma atuação complexa, pois atuar em processos na Vara da Fazenda Pública requer tempo devido ao excesso de recursos apresentados - tempo de que, em muitos dos casos, não se dispõe devido à gravidade/necessidade dos solicitantes. É considerável o aumento da judicialização 
nos últimos anos, reflexo da deficiência no gerenciamento estatal das políticas públicas de saúde. Porém, é inevitável recorrer à judicialização quando se trata da garantia de um direito subjetivo, constitucionalmente assegurado e indispensável para a manutenção da vida.

Os resultados obtidos neste estudo demonstram que o MPPE pode ser um dos responsáveis pela judicialização excessiva de interesses individuais subjetivos contra o SUS no interior do estado, mas que assim o faz por falta de alternativas e de capacitação profissional específica para o desenvolvimento de soluções consensuais dentro do próprio sistema público de saúde.

A última categoria identificada na pesquisa diz respeito à abordagem das políticas públicas de saúde nos cursos de bacharelado em Direito. Ao assumir a função de promotor, o bacharel em Direito devidamente aprovado em concurso para o cargo realiza um limitado curso introdutório, onde conhece as práticas de suas funções e tem o primeiro contato com as políticas públicas de saúde. Esse "contato tardio" dos membros do MPPE com as políticas públicas de saúde vem sendo um empecilho para seu trabalho cotidiano. Por unanimidade, todos os entrevistados relataram que, em sua formação acadêmica, não tiveram contato com disciplinas obrigatórias que abordassem temas relacionados diretamente à saúde. Apesar de terem o apoio do CAOP para a resolução de casos na área da saúde, é importante que os promotores tenham conhecimento mais aprofundado sobre a questão, afinal são os responsáveis por garantir o cumprimento efetivo dos direitos do cidadão.

Ao analisar os resultados da pesquisa, observa-se que existe uma fragilidade na compreensão dos membros do MPPE sobre as políticas públicas de saúde, evidenciando um campo pouco explorado em sua formação acadêmica e, consequentemente, refletindo em seu cotidiano de trabalho. Os resultados encontrados confirmam a hipótese inicial: o ensino do Direito apresenta-se falho na abordagem do tema da saúde. Considerando que as políticas públicas sociais podem ser diretrizes para a implementação de políticas públicas gerais, cabe uma abordagem mais aprofundada e direcionada na formação em Direito.

Existe uma escassez de estudos abordando a relação entre o MP e a Saúde Coletiva, pois trata-se de um campo "novo", de literatura deficiente. Estudar a compreensão que o MP tem sobre saúde, bem como os aspectos práticos e subjetivos que ela envolve, é fundamental para a construção e o desenvolvimento das ações relacionadas à cobrança da garantia do direito à saúde. Faz-se necessário o desenvolvimento de outras pesquisas em ambas as áreas de conhecimento, Direito e Saúde Coletiva, com o propósito de explorar esse rico e interessante campo de estudo, além de levar informações para a comunidade científica e o público geral sobre a indispensável relação existente entre MP e políticas públicas de saúde. 


\section{Referências}

AGUIAR, Zenaide Neto SUS: Sistema Único de Saúde: antecedentes, percurso, perspectivas e desafios. 2. ed. São Paulo: Martinari, 2015.

ASENSI, Felipe Dutra. Judicialização ou juridicização? As instituições jurídicas e suas estratégias na saúde. Physis, Rio de Janeiro, v. 20, n. 1, p. 33-55, 2010. http://dx.doi.org/10.1590/S010373312010000100004. Disponível em: http://www.scielo.br/pdf/physis/v20n1/a04v20n1.pdf.

AUGUSTO, Cleiciele Albuquerque et al. Pesquisa qualitativa: rigor metodológico no tratamento da teoria dos custos de transação em artigos apresentados nos congressos da Sober (2007-2011). Rev. Econ. Sociol. Rural, Brasília-DF, v. 51, n. 4, p. 745-764, dez. 2013. http://dx.doi.org/10.1590/ S0103-20032013000400007. Disponível em: http://www.scielo.br/scielo.php?script=sci_ arttext\&pid=S0103-20032013000400007\&lng=en\&nrm=iso. Acesso em: 01 nov. 2017.

BARROSO, Luís Roberto. Constituição, democracia e supremacia judicial: direito e política no Brasil contemporâneo. Revista da Faculdade de Direito da UERJ, Rio de Janeiro, v. 2, n. 21, p. 1-50, jan./jun. 2012. https://doi.org/10.12957/rfd.2012.1794. Disponível em: http:// www.e-publicacoes.uerj.br/index.php/rfduerj/article/view/1794. Acesso em: 06 nov. 2017.

CARVALHO, Ernani, LEITAO, Natália. O novo desenho institucional do Ministério Público e o processo de judicialização da política. Rev. direito GV, São Paulo, v. 6, n. 2, p. 399-422, dez. 2010. http://dx.doi.org/10.1590/S1808-24322010000200003. Disponível em: http://www. scielo.br/scielo.php?script=sci_arttext\&pid=S1808-24322010000200003\&lng=en\&nrm=iso. Acesso em: 15 nov. 2017.

CONSELHO NACIONAL DE SECRETARIAS MUNICIPAIS DE SAÚDE - CONASEMS. Carta de Palmas. In: CONGRESSO NORTE E NORDESTE DE SECRETÁRIOS MUNICIPAIS DE SAÚDE, 4., Palmas, 18-20 abr. 2016. Disponível em: http://www.conasems.org.br/wpcontent/uploads/2016/05/images_CARTA_DE_PALMAS.pdf. Acesso em: 02 out. 2016.

CONSELHO NACIONAL DE SECRETÁRIOS DE SAÚDE - CONASS. Legislação do SUS. 20. ed. Brasília-DF: CONASS, 2003. p. 22-38. Disponível em: http://bvsms.saude.gov.br/bvs/ publicacoes/progestores/leg_sus.pdf. Acesso em: 10 set. 2019.

GOULART, Marcelo Pedroso. Ministério Público: estratégia, princípios institucionais e novas formas de organização. In: LIVIANU, R. (Coord.). Justiça, cidadania e democracia [online]. Rio de Janeiro: Centro Edelstein de Pesquisa Social, 2009. p. 158-169. Disponível em: books. scielo.org/id/ff2x7/pdf/livianu-9788579820137-14.pdf. Acesso em: 10 out. 2017.

LUCCHESE, Patricia T. R (Coord.). Políticas públicas em saúde pública. São Paulo: BIREME/ OPAS/OMS, 2004. Disponível em: http://files.bvs.br/upload/M/2004/Lucchese_Politicas_ publicas.pdf. Acesso em: 20 set. 2017.

MARCUSCHI, Luiz Antônio. Compreensão textual como trabalho criativo. In: UNIVERSIDADE ESTADUAL PAULISTA. Prograd. Caderno de formação: formação de professores didática geral. São Paulo: Cultura Acadêmica, 2011. p. 89-103, v. 11. Disponível em: https://acervodigital.unesp.br/handle/123456789/40358. Acesso em: 10 out. 2017. 
MINISTÉRIO PÚBLICO DO ESTADO DO CEARÁ. Carta de Salvador em Defesa da Saúde. Salvador-BA, 27 ago. 2004. Disponível em: http://www.mp.ce.gov.br/orgaos/PROSAUDE/ cartas_declaracoes_salvador.html. Acesso em: 02 out. 2016.

MINISTÉRIO PÚBLICO DO ESTADO DO ESPÍRITO SANTO. Plano Nacional de Atuação Ministerial em Saúde Pública. 2006. Disponível em: https://www.mpes.mp.br/Arquivos/ Anexos/72bd6d29-2df4-433b-a821-c2cb7f15ce42.pdf. Acesso em: 19 out. 2019.

MINISTÉRIO PÚBLICO DO ESTADO DE PERNAMBUCO. Guia do Ministério Público de Pernambuco - Informações para a sociedade e a imprensa. Recife: Procuradoria Geral da Justiça, 2015. Disponível em: www.mppe.mp.br/mppe/attachments/article/5350/Manual\%20 MPPE\%20final\%20correto\%20site.pdf. Acesso em: 11 maio 2016.

OLIVEIRA, Gustavo Justino de. Efetivação do direito à saúde: ampliação do debate e renovação da agenda. Revista de Direito Sanitário, São Paulo, v. 16, n. 1, p. 78-86, jul. 2015. http://dx.doi. org/10.11606/issn.2316-9044.v16i1p78-86. Disponível em: http://www.revistas.usp.br/rdisan/ article/view/100024/98613. Acesso em: 30 out. 2017.

PAULA, Quenya Correa de; SANTOS, André Filipe Pereira Reid dos. Novos capitais em luta na magistratura Federal da $2^{\text {a }}$ Região. Quaestio Iuris, Universidade do Estado do Rio de Janeiro, Rio de Janeiro, v. 10, n. 4, p. 2616-2636, out. 2017. http://dx.doi.org/10.12957/ rqi.2017.28094. Disponível em: http://www.e-publicacoes.uerj.br/index.php/quaestioiuris/ article/view/28197/21901. Acesso em: 02 out. 2017.

PEPE, Vera Lúcia Edais et al. A judicialização da saúde e os novos desafios da gestão da assistência farmacêutica. Ciênc. saúde coletiva, Rio de Janeiro, v. 15, n. 5, p. 2405-2414, ago 2010. http://dx.doi. org/10.1590/S1413-81232010000500015. Disponível em: http://www.scielo.br/scielo.php?script=sci_ arttext\&pid=S1413-81232010000500015\&lng=en\&nrm=iso. Acesso em: 31 out. 2017.

RELATÓRIO Final da 10a Conferência Nacional de Saúde. "SUS - construindo um modelo de atenção à saúde para a qualidade de vida”. Brasília, 2-6 set. 1996. Coordenador da Comissão Organizadora Nelson Rodrigues dos Santos. Disponível em: bvsms.saude.gov.br/bvs/ publicacoes/10conferencia.pdf. Acesso em: 28 set. 2016.

TORRONTEGUY, Marco Aurélio Antas. A saúde nas barras da Justiça: um estudo do posicionamento recente do Supremo Tribunal Federal. Revista de Direito Sanitário, São Paulo, v. 11, n. 2, p. 224-236, out. 2010. Disponível em: https://www.revistas.usp.br/rdisan/article/ view/13215/15027. Acesso em: 31 out. 2017.

VENTURA, Miriam et al. Judicialização da saúde, acesso à justiça e a efetividade do direito à saúde. Physis, Rio de Janeiro, v.20, n. 1, p. 77-100, 2010. http://dx.doi.org/10.1590/ S0103-73312010000100006. Disponível em: http://www.scielo.br/scielo.php?script=sci_ arttext\&pid=S0103-73312010000100006\&lng=en\&nrm=iso. Acesso em: 30 out. 2017.

WERNER, Patrícia Ulson Pizarro. O direito social e o direito público subjetivo à saúde: $\mathrm{o}$ desafio de compreender um direito com duas faces. Revista de Direito Sanitário, São Paulo, v. 9, n. 2, p. 92-131, jul 2008. Disponível em: http://www.periodicos.usp.br/rdisan/article/ view/13119/14922. Acesso em: 06 nov. 2017. 
Santana V. J., Nunes J. R. V.

Valdilene Josefa de Santana - Pós-Graduanda Lato Sensu em Avaliação em Saúde Aplicada à Vigilância pela Universidade Federal de Pernambuco (UFPE); bacharel em Saúde Coletiva pela UFPE. Recife/PE, Brasil. E-mail: valdilenedesantana@gmail.com

José Ronaldo Vasconcelos Nunes - Doutorando em Educação pela Universidade Federal de Pernambuco (UFPE); mestrado em Saúde Coletiva pela UFPE; especialização lato sensu em Saúde Pública, Gestão de Sistemas e Ações de Saúde pela Universidade de Pernambuco (UPE); graduação em Enfermagem pela UFPE. Professor assistente do bacharelado em Saúde Coletiva da UFPE. Recife/PE, Brasil. E-mail: ronatriunfo@yahoo.com.br 